\title{
Adequacy of Thyroid Hormone Replacement in a Tertiary Care Hospital in Nepal-An Observational Study
}

\author{
Shrestha H K ${ }^{1}$, Tamrakar R ${ }^{2}$, Shrestha $\mathrm{A}^{3}$, Uprety $\mathrm{M}^{4}$, Shrestha $\mathrm{B}^{5}$ \\ ${ }^{1}$ Consultant Endocrinologist, Physician, Siddha Baba Superspeciality Hospital, Butwal, Nepal, ${ }^{2}$ lecturer, \\ Kathmandu University Hospital, Dhulikhel Hospital, Nepal, ${ }^{3}$ Lecturer, Kathmandu University Hospital, \\ Dhulikhel Hospital. Nepal, ${ }^{4}$ Medical Officer, Birta City Hospital, Birtamode, Nepal, ${ }^{5}$ Medical Officer, \\ Helping Hand Hospital, Chabahil
}

\begin{abstract}
Background: The therapeutic goal in hypothyroidism is to achieve patients' well-being and restore serum thyrotropin (TSH) to levels within the reference range. However, inadequate or over replacement is common in patients receiving levothyroxine. The Objective is to assess the treatment outcome of hypothyroid patients visiting outpatient clinic of medicine department of Kathmandu University Hospital, Dhulikhel, Nepal. Method: This is a cross sectional study on diagnosed Primary Hypothyroid patients who were taking levothyroxine replacement for at least six months. Patients were defined as euthyoid if their TSH was in the normal range $(0.3-3.6 \mathrm{mmol} / \mathrm{L})$ according to the hospital laboratory. Similarly patients were defined as over treated if TSH is $<0.3 \mathrm{mmol} / \mathrm{L}$ and undertreated if TSH is $>3.6 \mathrm{mmol} / \mathrm{L}$. Results: A total number of 126 patients were enrolled for this study where mean age of participants was $40.88 \pm 11.47$ years and only $15(11.1 \%)$ were male. Mean duration of hypothyroidism was $3.45 \pm 2.57$ years and mean Levothyroxine dose was $58.93 \pm 26.89 \mathrm{mcg}$. In this study, nearly $70 \%$ of participants have normal TSH level. Similarly, 21\% of participants have higher level of TSH and $9 \%$ have low TSH level. Multivariate logistic regression analysis did not show any significant co relation between treatment outcome and various variables. Conclusion: Treatment of hypothyroidism with levothyroxine being most effective, easily available, simple regimen and not costly, still one third of patients are not meeting the treatment outcome. However, being the pioneer study from Nepal, this study suggests improved treatment outcomes compared to similar studies from other countries.
\end{abstract}

\section{Keywords: Primary Hypothyroidism, Treatment Outcome, Levothyroxine}

\section{Introduction}

Diseases of the thyroid gland are amongst the most abundant endocrine disorder in the world second only to diabetes mellitus. ${ }^{1}$ The spectrum of thyroid disorders includes hypothyroidism, subclinical hypothyroidism, hyperthyroidism and subclinical hyperthyroidism. The worldwide prevalence of

\section{Correspondence Author}

Shrestha Hari Kumar, Consultant Endocrinologist, Physician, Siddha Baba Superspeciality Hospital, Butwal, Nepal

Email: drhariks676@gmail.com spontaneous overt hypothyroidism is between $1 \%$ and $2 \%$ and ten times more common in women than in men. ${ }^{2}$ The prevalence of overt hypothyroidism has been reported between $3.5 \%$ and $4.2 \%$ in various studies across India. ${ }^{3,4}$ Several studies in different parts of Nepal showed wide variation in prevalence of the thyroid dysfunctions. ${ }^{5,6,7}$

Thyroid hormone replacement with synthetic levothyroxine is the treatment of choice for hypothyroidism, commonest thyroid disorder. ${ }^{3-7}$ The therapeutic goal in hypothyroidism is to achieve 
patients' well-being and restore serum thyrotropin (TSH) to levels within the reference range. ${ }^{8}$

However, inadequate or over replacement is common in patients receiving levothyroxine. ${ }^{9,10}$ Abnormal thyroid function tests were also detected in a third of patients who self-reported thyroid disease or use of thyroid medications in the National Health and Nutritional Examinations Survey (NHANES III). ${ }^{11}$ Likewise, a study in older levothyroxine users showed that only $43 \%$ were biochemically euthyroid. ${ }^{12}$ Unfortunately, to the best of our knowledge, we do not have outcome study on diagnosed hypothyroid patients from Nepal. Thus, this study aim to assess the treatment outcome of hypothyroid patients visiting outpatient clinic of medicine department of Kathmandu University Hospital, Dhulikhel, Nepal.

\section{Methods}

This is a cross sectional study on diagnosed Primary Hypothyroid patients attending the Medicine OPD of Dhulikhel Hospital, Kathmandu University Hospital from November 2017 to April 2018. People aged 18 years or above and who are taking Levothyroxine for at least 6 months were included in this study. Once patients visit the outpatient clinic of medicine, their socio-demographic data including duration of hypothyroidism, recent TSH level, medicine they are taking, current dose and lab investigations are documented in one demography form after written consent. Patients were defined as euthyoid if their TSH was in the normal range (0.3$3.6 \mathrm{mmol} / \mathrm{L}$ ) according to the hospital laboratory. Similarly patients were defined as over treated if TSH is $<0.3 \mathrm{mmol} / \mathrm{L}$ and undertreated if TSH is $>3.6 \mathrm{mmol} / \mathrm{L}$. Adherence to Thyroxine therapy was assessed by asking the patients the number of doses missed in the last 1 month and was categorized as non-adherent if misses $>15 \%$ of doses in last month. ${ }^{13}$ Data was analyzed using SPSS version 21.0 for windows. Descriptive statistics, such as frequency, percentage, mean and standard deviation was used to summarize patients' baseline characteristics. Multivariable logistic regression model was fitted to determine independent predictors of treatment outcome when the p-value $\leq 0.1$ on bivariate analysis. Statistical significance was considered at $p$-value $<0.05$. This study was approved by KUSMS-IRC.

\section{Results}

A total number of 126 patients were enrolled for this study whose characteristics variables are shown on Table 1 . The mean age of participants was 40.88 \pm 11.47 years, where only 15 (11.1\%) were male. Majority of them (62\%) have education level below SLC. Mean duration of hypothyroidism was 3.45 \pm 2.57 years and mean Levothyroxine dose was $58.93 \pm 26.89 \mathrm{mcg}$. All of the participants were neither smoker nor alcoholic. Likewise, none of the participants were non adherent in this study.

Forty percentage of participants were on Levothyroxine $50 \mathrm{mcg}$. Likewise, $23 \%$ of participants were on Levothyroxine 25 and $50 \mathrm{mcg}$ each as shown on (figure 1).

In this study, nearly $70 \%$ of participants have normal TSH level. Similarly, 21\% of participants have higher level of TSH and 9\% have low TSH level as shown in (figure 2). Multivariate logistic regression analysis did not show any significant co relation between treatment outcome and age, gender, education level, disease duration, other comorbid conditions. 
Table 1: Characteristics of participants

\begin{tabular}{|c|c|}
\hline Variables & $\begin{array}{l}\text { Mean } \pm \text { SD / } \\
\text { Number }(\%)\end{array}$ \\
\hline Age (years) & $40.88 \pm 11.47$ \\
\hline \multicolumn{2}{|l|}{ Gender } \\
\hline Male & $15(11.1 \%)$ \\
\hline Female & $111(88.1 \%)$ \\
\hline \multicolumn{2}{|l|}{ Education } \\
\hline Below SLC & $78(61.9 \%)$ \\
\hline Intermediate & $21(16.66 \%)$ \\
\hline Bachelor \& above & $27(21.44 \%)$ \\
\hline $\begin{array}{l}\text { Duration of Hypothyroidism } \\
\text { (years) }\end{array}$ & $3.45 \pm 2.57$ \\
\hline TSH level (current) & $3.36 \pm 2.84$ \\
\hline Free T4 level (mmol/L) & $1.05 \pm 0.24$ \\
\hline $\begin{array}{l}\text { Daily Levothyroxine Dose } \\
\text { (Mcg) }\end{array}$ & $58.93 \pm 26.89$ \\
\hline Weight (Kg) & $63.83 \pm 15.07$ \\
\hline \multicolumn{2}{|l|}{ Blood Pressure } \\
\hline $\mathrm{SBP}(\mathrm{mmHg})$ & $81.61 \pm 15.78$ \\
\hline $\mathrm{DBP}(\mathrm{mmHg})$ & $81.61 \pm 15.78$ \\
\hline Total Cholesterol (mmol/L) & $171.83 \pm 68.89$ \\
\hline $\mathrm{HDL}(\mathrm{mmol} / \mathrm{L})$ & $43.01 \pm 19.37$ \\
\hline $\mathrm{LDL}(\mathrm{mmol} / \mathrm{L})$ & $98.66 \pm 42.54$ \\
\hline $\mathrm{TG}(\mathrm{mmol} / \mathrm{L})$ & $145 \pm 72.07$ \\
\hline Diabetes Mellitus & $9(7.12 \%)$ \\
\hline Hypertension & $9(7.12 \%)$ \\
\hline Dyslipidemia & $9(7.12 \%)$ \\
\hline
\end{tabular}

Percentage of Patients with L-Thyroxine Dose

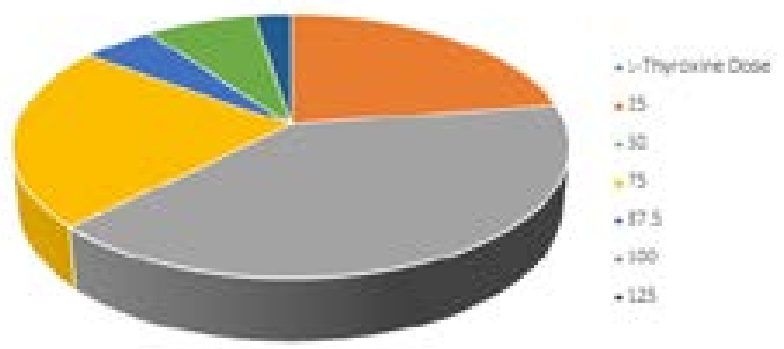

Figure 1: Proportion of patients taking daily Levothyroxine dose
No of Patients with TSH level

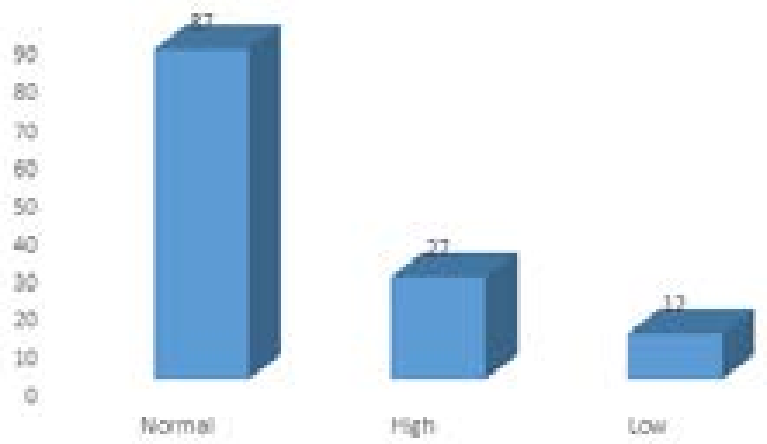

Figure 2: Number of patients based on TSH level

\section{Discussion}

In this study, almost $70 \%$ of participants have achieved euthyroid status, similar to the National Health and Nutritional Examinations Survey ${ }^{14}$ and a general population study ${ }^{15}$ published on 2011 . Several other studies have shown that less than half of hypothyroid patients achieved euthyroid status despite of regular dose titration and follow up ${ }^{13,16,17}$. The proportion of undertreated hypothyroid patients was $21 \%$ in our study ${ }^{15}$, which was $17 \%$ and much higher to other studies up to $45 \%{ }^{13,16,17}$. Nearly $20 \%$ of participants had over replacement in one study ${ }^{15}$, in contrast which was only $9 \%$ in this study, similar to the other studies ${ }^{13,17}$. Whatever the percentage, there is similar trend on treatment outcome between various studies that overtreatment being the least prevalent.

Both under and over replacement with levothyroxine could lead to potential unwanted consequences. Hypothyroidism is associated with harmful effects on body weight ${ }^{18}$, lipid profile ${ }^{19}$, blood pressure ${ }^{20}$, and increased risk of sleep apnea ${ }^{21}$.

The mean daily dose of levothyroxine in this study was $0.92 \mathrm{mcg} / \mathrm{Kg}$. This dose is much lower to the daily recommended dose of $1.6 \mathrm{mcg} / \mathrm{Kg}$ by various western guidelines such as the American Thyroid Association and American Association of Clinical Endocrinologists guidelines ${ }^{22}$. There is one Asian 
study from Singapore stating mean daily dose of levothyroxine was $1.1 \mathrm{mcg} / \mathrm{kg}^{17}$. In addition, this study also found that participants who were over replaced had a higher daily levothyroxine dose of $1.4 \mathrm{mcg} / \mathrm{kg}$. Similarly this daily levothyroxine dose was $1.23 \mathrm{mcg} / \mathrm{kg}$ in an Indian study ${ }^{13}$.

Similar daily dose of levothyroxine in the euthyroid and under replaced group was seen in our study, similar to the study from Singapore, which suggests that the under replacement may be due to factors other than dosages, such as medication adherence and decreased bioavailability. However no participants reported non adherent in this study; in contrast it was 10\% in an Indian study ${ }^{13}$ and 51.5\% in another study ${ }^{17}$.

\section{Strength and limitations}

To the best of our knowledge, this is the first study from Nepal on treatment outcome of primary hypothyroid patients. It highlighted the actual scenario of treatment outcome of primary hypothyroidism especially the magnitude of levothyroxine under and over replacement among this population. This study can be regarded as a pilot study especially on advocating the daily replacement dose of levothyroxine among Nepalese population.

Nevertheless, it has limitations. This is a cross sectional study and only provides a snapshot of the state of the management of condition, so it can not reflect the dynamic nature of the clinical practices amongst the physicians to achieve euthyroidism. Likewise, small sample size and only enrolling patients from a tertiary hospital may not be the representative data of Nepal.

\section{Conclusion}

Treatment of hypothyroidism with levothyroxine being most effective, easily available, simple regimen and not costly, still one third of patients are not meeting the treatment outcome. However, being the pioneer study from Nepal, this study suggests improved treatment outcomes compared to similar studies from the other part of the world.

\section{Acknowledgments}

We would like to thank our patient for being very cooperative during the entire work. We would also like to thank other team members from the internal medicine department of Dhulikhel Hospital.

\section{Conflicts of interest}

The author declares there is no conflict of interest.

\section{Declarations}

\section{List of abbreviations}

TSH: Thyroid Stimulating Hormone

NHANES: National Health and Nutritional Examinations Survey

OPD: Outpatient Department

SPSS: Statistical Package for The Social Sciences KUSMS IRC: Kathmandu University School of Medical Sciences Institutional Review Comitee

SD: Standard Deviation

OPD: Outpatient Department

SD: Standard Deviation

SLC: School Leaving Certificate

LDL: Low Density Lipoprotein

HDL: HIgh Density Lipoprotein

TG: Triglyceride

SBP: Systolic Blood Pressure

DBP: DIastolic Blood Pressure

\section{Ethics approval}

The study was conducted after the ethical approval from the Institutional Review Committee,Kathmandu University School of Medical Sciences. Participants were explained about the research detail, its significance, the benefit and harm in Nepali language before obtaining the consent, their queries were answered. A statement indicating that the participants have understood all the information in the consent form and are willing to participate voluntarily was obtained. Participants were able to withdraw from the study at any time without giving any reason during the study period. The confidentiality of participants was assured and code number was used in each interview schedule and name of the participants was not mentioned anywhere. 


\section{Consent for publication}

Not applicable

\section{Competing interests}

The authors declare that they have no competing interests.

\section{Funding}

Not applicable

\section{Authors' contributions}

HKS: conceptualized, collected data, analyzed and wrote the manuscript. RT: collected data, AS: collected data. MU: collected data and analyzed, BS: analyzed data. All authors read and approved the final manuscript.

\section{Acknowledgements}

We thank all the respondents without whom we would not have been able to share this effort.

\section{References}

1. Heuck CC, Kallner A, Kanagasabapathy A S, Riesen W, Diagnosis \& monitoring of the disease of the thyroid. WHO Document 2000; 8-9.

2. Vanderpump MP, Tunbridge WM, French JM, Appleton D, Bates D, Clark F, et al. The incidence of thyroid disorders in the community: A twenty-year follow-up of the Whickham Survey. Clin Endocrinol (Oxf) 1995;43:55-68.

3. Marwaha RK, Tandon N, Ganie MA, Kanwar R, Sastry A, Garg MK, et al. Status of thyroid function in Indian adults: Two decades after universal salt iodization. J Assoc Physicians India 2012;60:32-6.

4. Kalra S, Kumar A, Jarhyan P, Unnikrishnan AG. Indices of thyroid epidemiology. Indian J Endocrinol Metabol 2015;19:844-7.

5. Mahato RV, Nepal AK, Gelal B, et al. Spectrum of thyroid dysfunction in patients visiting Kantipur hospital, thmandu, Nepal. Mymensingh Med J 2013;2:164-69.

6. Aryal M, Gywali P, Rajbhandari N, et al. A prevalence of thyroid dysfunction in
Kathmandu University Hospital, Nepal. edical Research 2010; 21: 411-15.

7. Adhikari BR, Twayana RS, Shrestha S, Vaidya N, Aghrahari M, Ghimire B - Pattern of thyroid disorders in people from central Nepal: A Hospital based study - published at: "International Journal of Scientific and Research Publications (IJSRP), Volume 7, Issue 8, August 2017 Edition".

8. Vaidya B, Pearce SH. Management of hypothyroidism in adults, BMJ , 2008, vol. 337 pg. a801.

9. Somwaru LL, Arnold AM, Joshi N, Fried LP, Cappola AR. High frequency of and factors associated with thyroid hormone overreplacement and under-replacement in men and women aged 65 and over. J Clin Endocrinol Metab 2009; 94: 1342-5.

10. O.E. Okosieme, G. Belludi, K. Spittle, R. Kadiyala, J. Richards; Adequacy of thyroid hormone replacement in a general population, QJM: An International Journal of Medicine, Volume 104, Issue 5, 1 May 2011, Pages 395401.

11. Hollowell JG, Staehling NW, Flanders WD, Hannon WH, Gunter EW, Spencer CA, et al. . Serum TSH, T(4), and thyroid antibodies in the United States population (1988 to 1994): National Health and Nutrition Examination Survey (NHANES III), J Clin Endocrinol Metab , 2002, vol. 87 (pg. 489-99).

12. Somwaru LL, Arnold AM, Joshi N, Fried LP, Cappola AR. High frequency of and factors associated with thyroid hormone overreplacement and under-replacement in men and women aged 65 and over, J Clin Endocrinol Metab , 2009, vol. 94 (pg. 1342-5).

13. Mithal A, Dharmalingam M, Tewari N. Are patients with primary hypothyroidism in India receiving appropriate thyroxine replacement? An observational study. Indian J Endocrinol Metab 2014;18:83-8.

14. Hollowell JG, Staehling NW, Flanders WD, Hannon WH, Gunter EW, Spencer CA, et al. Serum TSH, T(4), and thyroid antibodies in 
the United States population (1988 to 1994): National Health and Nutrition Examination Survey (NHANES III) J Clin Endocrinol Metab. 2002;87:489-99.

15. Okosieme OE, Belludi G, Spittle K, Kadiyala R, Richards J. Adequacy of thyroid hormone replacement in a general population. QJM. 2011;104(5):395-401.

16. Dilek Gogas Yavuz, Dilek Yazici, Lezzan Keskin, et al. Out-of-Reference Range Thyroid-Stimulating Hormone Levels in Levothyroxine-Treated Primary Hypothyroid Patients: A Multicenter Observational Study. Front Endocrinol. 2017;8: 215.

17. Tan, Ngiap Chuan et al. "Primary hypothyroidism in the community: Lower daily dosages of levothyroxine replacement therapy for Asian patients." Medicine vol. 96,7 (2017): e6145. doi:10.1097/MD.0000000000006145.
18. Baron DN. Hypothyroidism; its aetiology and relation to hypometabolism, hypercholesterolaemia, and increase in bodyweight. Lancet 1956;271:277-81.

19. Duntas LH. Thyroid disease and lipids. Thyroid 2002;12:287-93.

20. Fommei E, Iervasi G. The role of thyroid hormone in blood pressure homeostasis: evidence from short-term hypothyroidism in humans. J Clin Endocrinol Metab 2002;87:1996-2000.

21. Jha A, Sharma SK, Tandon N, et al. Thyroxine replacement therapy reverses sleepdisordered breathing in patients with primary hypothyroidism. Sleep Med 2006;7:55-61.

22. Jonklaas J, Bianco AC, Bauer AJ, et al. Guidelines for the treatment of hypothyroidism: prepared by the American Thyroid Association task force on thyroid hormone replacement. Thyroid 2014;24:1670-751. 